\title{
PENENTUAN PRODUK UNGGULAN DAERAH PADA SENTRA INDUSTRI KECIL MENENGAH DI KABUPATEN BONDOWOSO
}

\author{
Moh. Erfan Arif \\ Departemen Manajemen Fakultas Ekonomi dan Bisnis Universitas Brawijaya \\ erfan_arif@ub.ac.id
}

Masuk : 30-01-2021, revisi : 20-02-2021 diterima untuk diterbitkan : 22-02-2021

\begin{abstract}
This study aims to determine the Regional Superior Products (PUD) in Bondowoso Regency, East Java Province. Bondowoso Regency has several industrial centers that produce regional potential products that can become superior products. The potential industrial centers include coffee, tape, brass, furniture, baskets, iron crafts, embroidery, chips, tiles, batik, and bricks. The determination of this regional superior product refers to Permendagri Number 9 of 2019 concerning Regional Superior Product Development. This research method is descriptive qualitative with the method of collecting data through interviews. The results showed that the potential industrial centers that were eligible to be designated as regional superior products were the tape industry centers. The industrial centers that produce these tapes are the most appropriate to be designated as Bondowoso Regency's Superior Products because they are the most suitable and reflect the criteria of regional superior products according to Permendagri number 9 of 2019. The results of the determination of the superior products of this region can be used as a basis in the preparation of potential industrial center development programs to increase regional economic growth.
\end{abstract}

Keywords: PUD, Industrial Center, Permendagri Number 9 Of 2014, Tape Industry Center

\begin{abstract}
Abstrak: Penelitian ini bertujuan untuk menentukan Produk Unggulan Daerah (PUD) di Kabupaten Bondowoso Provinsi Jawa Timur. Kabupaten Bondowoso memiliki beberapa sentra industri yang menghasilkan produk-produk potensial daerah yang dapat menjadi produk unggulan. Sentra-sentra industri potensial tersebut antara lain: kopi, tape, kuningan, mebel, besek, kerajinan besi, bordir, keripik, genteng, batik, dan batu bata. Penentuan produk unggulan daerah ini mengacu Permendagri Nomor 9 Tahun 2019 tentang Pengembangan Produk Unggulan Daerah. Metode penelitian ini adalah deskriptif kualitatif dengan metode pengumpulan data melalui wawancara. Hasil penelitian menunjukkan bahwa sentra industri potensial yang layak ditetapkan sebagai produk unggulan daerah adalah sentra industri tape. Sentra industri yang menghasilkan tape ini paling layak ditetapkan sebagai Produk Unggulan Daerah Kabupaten Bondowoso karena paling sesuai dan mencerminkan kriteria-kriteria produk unggulan daerah sesuai Permendagri Nomor 9 Tahun 2019. Hasil penentuan produk unggulan daerah ini dapat dijadikan dasar dalam penyusunan program pengembangan sentra industri potensial untuk meningkatkan pertumbuhan ekonomi daerah.
\end{abstract}

Kata Kunci: PUD, Sentra Industri, Permendagri Nomor 9 Tahun 2014, Sentra Industri Tape

\section{PENDAHULUAN}

Konsep One Village One Product (OVOP) pertama kali diinisiasi oleh Dr. Morihiko Hiramatsu di Provinsi Oita-Jepang pada 1979. OVOP merupakan pendekatan pengembangan potensi daerah di satu wilayah untuk menghasilkan produk yang mampu bersaing di pasar baik lokal, nasional maupun global. Produk yang dikembangkan memiliki keunikan karakteristik dari daerah tersebut. Produk yang dihasilkan adalah produk yang proses pembuatannya memanfaatkan sumber daya lokal, baik sumber daya alam, maupun sumber daya manusia (Triharini, et al., 2014; Schumann, 2016). 
Konsep OVOP ini kemudian menginspirasi dikembangkannya konsep Produk Unggulan Daerah (PUD) di Indonesia. Konsep PUD ini diyakini akan dapat memberikan dampak positif bagi perekonomian daerah. Komoditas unggulan daerah dapat memberikan nilai tambah dan sumbangan pertumbuhan ekonomi yang besar bagi daerah dan Produk Domestik Bruto (Husen, 2011; Pantow, et al, 2015; Zelesko, 2017; Syafaat dan Supena, 2000). Selain itu, produk unggulan daerah (lokal) merupakan pendorong untuk pengembangan ekonomi regional terutama di daerah pedesaan (Messely, et al, 2009).

Pengembangan PUD masih menghadapi beberapa permasalahan seperti lemahnya sistem pendukung produk unggulan yang meliputi sumberdaya manusia, permodalan, pemasaran, difusi Ipteks, kemitraan usaha, infrastruktur, dan kelembagaan (Triharini, et. al, 2014). Produk lokal juga cenderung memiliki harga tinggi (Salisbury, et al, 2018) dan (Donaher \& Lynes, 2017) karena proses produksi sederhana menghasilkan produk berkualitas rendah. Oleh karena itu, pemerintah memiliki peran penting dalam mendukung agen ekonomi (khususnya UKM) untuk menghasilkan barang dan jasa yang memenuhi karakteristik lokal yang unggul (Nakagawa, 2012); (Niskha \& Vesala, 2013); dan (Sambajee \& Dhomun, 2015).

Kabupaten Bondowoso memiliki sejumlah sentra produk Usaha Kecil dan Menengah (UKM) yang potensial untuk menjadi produk unggulan daerah. Komoditas-komoditas potensial tersebut antara lain kopi, tape, kuningan, mebel, besek, kerajinan besi, bordir, keripik dan lain-lain. Kabupaten Bondowoso perlu menentukan produk unggulan daerah untuk dikembangkan agar masyarakat lebih mandiri (Takdir, 2012). Selain itu, produk unggulan lokal yang menjadi identitas daerah akan mampu menjadi faktor pendorong untuk pengembangan ekonomi regional terutama di daerah pedesaan (Messely, et al, 2009).

Pengembangan produk unggulan daerah tidak dapat dipisahkan dari peran UKM sebagai entitas industri di suatu daerah. UKM memiliki peran penting dalam siklus ekonomi, sebagai sumber pertumbuhan dan pembangunan ekonomi berkelanjutan melalui penciptaan lapangan kerja, pengurangan kemiskinan, dan peningkatan tenaga kerja terampil (Karadag, 2016). Selain itu, UKM dapat memfasilitasi pengembangan industri dan peningkatan serta pengembangan kapasitas produksi (Oduntan, 2014) dan nilai tambah produk yang tinggi untuk kepuasan konsumen (Hobohm, 2017). Dalam penentuan produk unggulan daerah tentunya mengacu pada Peraturan Menteri Dalam Negeri RI Nomor 9 Tahun 2014 tentang Pedoman Pengembangan Produk Unggulan Daerah.

\section{TELAAH KEPUSTAKAAN}

Produk Unggulan Daerah (PUD) memiliki pengertian yang luas karena dilihat dari berbagai perspektif. Ahmadjayadi (2001) menjelaskan PUD adalah unggulan daerah yang memiliki ciri khas dan keunikan yang tidak dimiliki daerah lain serta berdaya saing handal dan dapat memberikan peluang kesempatan kerja kepada masyarakat lokal. Produk unggulan daerah juga berorientasi ramah lingkungan dan berorientasi pada pasar baik lokal maupun nasional dan regional. Produk unggulan daerah juga yang memiliki peluang pemasaran yang tinggi dan menguntungkan masyarakat pedesaan (Suyanto, 1999) yang memanfaatkan sumber daya lokal, meningkatkan pendapatan masyarakat lokal, memiliki kemampuan menyediakan lapangan kerja lokal, bertujuan untuk industri yang lebih mapan, dan memiliki kemampuan untuk memanfaatkan tenaga kerja muda sebagai sumber inovasi (Latif, 2009).

Menurut Peraturan Menteri Dalam Negeri RI Nomor 9 Tahun 2014 tentang Pedoman Pengembangan Produk Unggulan Daerah, produk unggulan daerah adalah Produk baik berupa barang maupun jasa, yang dihasilkan oleh koperasi, usaha skala kecil dan menengah yang potensial untuk dikembangkan dengan memanfaatkan semua sumberdaya yang dimiliki oleh daerah baik sumberdaya alam, sumberdaya manusia dan budaya lokal, serta mendatangkan pendapatan bagi masyarakat maupun pemerintah yang diharapkan menjadi kekuatan ekonomi bagi daerah dan masyarakat setempat sebagai produk yang potensial memiliki daya saing, daya jual dan daya dorong menuju dan mampu memasuki pasar global. 
Porter (1985) menyebutkan bahwa produk unggulan harus memiliki elemen penunjang yang kuat setidaknya pada dua faktor kunci, yaitu: pertama, faktor kondisi, seperti bahan baku, ketrampilan tenaga kerja/tenaga ahli, pembiayaan, teknologi, transportasi, dan komunikasi. Kedua, faktor permintaan, yaitu keterkaitan dengan hulu dan hilir. Ambardi dan Socia (2002) menentukan kriteria komoditas daerah layak disebut sebagai produk unggulan ketika memenuhi syarat: mampu menjadi penggerak utama pembangunan perekonomian, mempunyai keterkaitan ke depan dan ke belakang yang kuat, mampu bersaing dengan produk sejenis dari wilayah lain di pasar nasional dan internasional, baik dalam harga produk, biaya produksi, kualitas pelayanan, maupun aspek-aspek lainnya.

Alkadri, et al, (2001) lebih luas dalam menentukan kriteria untuk menentukan produk unggulan bagi suatu daerah yaitu mampu menjadi penggerak utama pertumbuhan ekonomi, mempunyai keterkaitan ke depan dan ke belakang, mampu bersaing di pasar nasional dan internasional, memiliki keterkaitan dengan wilayah lain baik dalam hal pasar maupun pasokan bahan baku, memiliki teknologi yang terus meningkat, mampu menyerap tenaga kerja secara optimal, dapat bertahan dalam jangka panjang, tidak rentan terhadap gejolak eksternal dan internal, pengembangannya harus mendapatkan berbagai bentuk (keamanan, sosial, budaya, informasi dan peluang pasar, kelembagaan, fasilitas insentif/disinsentif, dan lainnya) dan pengembangannya berorientasi kelestarian sumberdaya dan lingkungan.

\section{METODOLOGI PENELITIAN}

Jenis penelitian dalam penentuan produk unggulan daerah ini adalah penelitian kualitatif. Data dikumpulkan dari responden menggunakan kuesioner dan wawancara kepada pelaku usaha tentang variabel yang menjadi perhatian. Data yang dikumpulkan digunakan untuk mendeskripsikan karakteristik dari populasi tertentu (Mc Millan dan Schumacher, 2001). Penelitian ini diawali dengan Focus Group Discussion (FGD) yang melibatkan para pelaku usaha pada masing-masing sentra industri yang difasilitasi oleh Diskoperindag Kabupaten Bondowoso. Pertanyaan yang diajukan dalam wawancara merujuk pada kriteria produk unggulan sesuai Permendagri Nomor 9 Tahun 2014 dengan indikator penyerapan tenaga kerja, sumbangan terhadap perekonomian, sektor basis ekonomi daerah, dapat diperbaharui, sosial budaya, ketersediaan pasar, bahan baku, modal, sarana dan prasarana produksi, teknologi, manajemen usaha, dan harga. Masing-masing indikator yang merupakan penjabaran dari kriteria atau variabel produk unggulan diberi bobot nilai 1 sampai 3. Angka yang lebih besar menunjukkan tingkat urgensi indikator tersebut dalam penentuan produk unggulan. Setelah diberi bobot pada masing-masing indikator sebagaimana yang disampaikan oleh informan, selanjutnya dilakukan penjumlahan untuk menghasilkan peringkat produk unggulan daerah.

\section{ANALISA \& PEMBAHASAN}

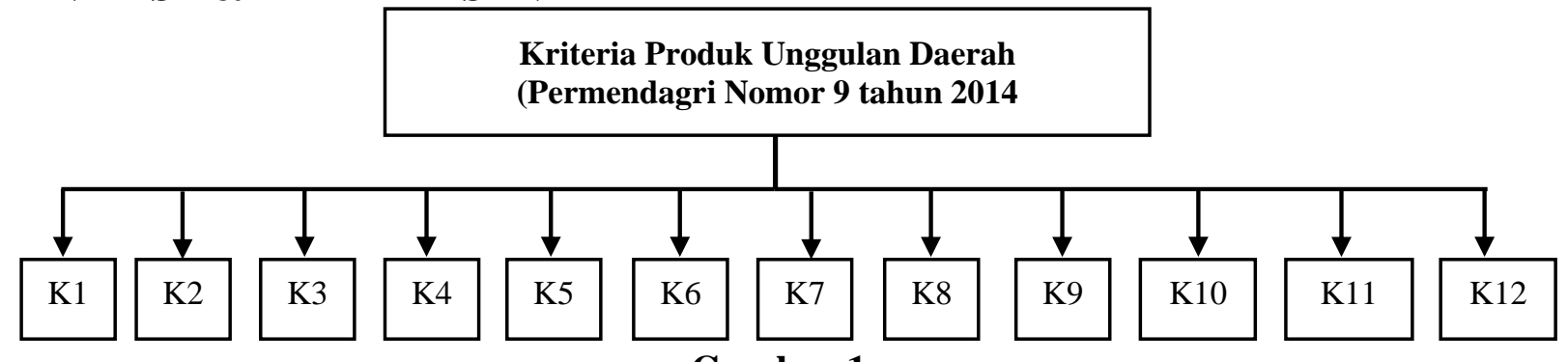

Gambar 1

\section{Keterangan:}

Kriteria Produk Unggulan Daerah (Permendagri Nomor 9 Tahun 2014)

$\mathrm{K} 1$ = penyerapan tenaga kerja

$\mathrm{K} 2$ = sumbangan terhadap perekonomian

$\mathrm{K} 3$ = sektor basis ekonomi daerah

$\mathrm{K} 4$ = dapat diperbaharui
K5 = sosial budaya

$\mathrm{K} 6=$ ketersediaan pasar

$\mathrm{K} 7$ = bahan baku

$\mathrm{K} 8=$ modal
$\mathrm{K} 9$ = sarana produksi

$\mathrm{K} 10$ = teknologi

$\mathrm{K} 11$ = manajemen usaha

$\mathrm{K} 12$ = harga 
Tabel 1

Hasil Pemeringkatan Produk Unggulan Daerah Kabupaten Bondowoso 2019

\begin{tabular}{|c|c|c|c|c|c|c|c|c|c|c|c|c|c|c|c|}
\hline NO & INDIKATOR & ITEM PERTANYAAN & Tape & Besek & Tahu & Keripik & Besi & Genteng & Batu Bata & Gerabah & Bordir & Batik & Mebel & Kuningan & Jumlah \\
\hline \multirow{2}{*}{1} & \multirow{2}{*}{$\begin{array}{l}\text { Penyerapan Tenaga } \\
\text { Kerja }\end{array}$} & - Jumlah Tenaga Kerja Terserap & 2 & 3 & 1 & 1 & 1 & 2 & 2 & 1 & 2 & 1 & 2 & 2 & 20 \\
\hline & & - Menggunakan Tenaga Kerja Trampil & 2 & 2 & 2 & 2 & 3 & 2 & 2 & 3 & 3 & 3 & 2 & 3 & 29 \\
\hline \multirow{6}{*}{2} & \multirow{6}{*}{ Sumbangan Ekonomi } & - Banyak Sentra Industri & 2 & 3 & 1 & 1 & 2 & 2 & 1 & 1 & 1 & 1 & 2 & 2 & 19 \\
\hline & & - Jumlah Pengrajin & 2 & 3 & 1 & 2 & 1 & 3 & 3 & 1 & 1 & 1 & 2 & 2 & 22 \\
\hline & & - Kontribusi Ekonomi Lokal & 3 & 3 & 3 & 3 & 1 & 3 & 3 & 1 & 3 & 1 & 2 & 2 & 28 \\
\hline & & - Keterkaitan ke Depan dan Belakang & 3 & 3 & 3 & 3 & 2 & 2 & 2 & 2 & 3 & 1 & 1 & 2 & 27 \\
\hline & & - Ragam Multiplier Effect Stakeholder & 3 & 2 & 3 & 3 & 2 & 2 & 2 & 2 & 2 & 1 & 2 & 2 & 26 \\
\hline & & - Hasil Produksi (Ton/Buah/Tampan) & 3 & 3 & 3 & 3 & 3 & 3 & 3 & 2 & 2 & 1 & 2 & 2 & 30 \\
\hline \multirow{5}{*}{3} & \multirow{5}{*}{ Sektor Basis } & - Bahan Baku Lokal & 3 & 3 & 3 & 3 & 1 & 3 & 3 & 3 & 2 & 3 & 2 & 2 & 31 \\
\hline & & - Ketersediaan SDM/Skill Lokal & 3 & 3 & 3 & 3 & 1 & 3 & 3 & 3 & 2 & 2 & 3 & 3 & 32 \\
\hline & & - Andalan Penghasilan Masyarakat & 3 & 3 & 3 & 3 & 1 & 3 & 3 & 3 & 3 & 3 & 2 & 2 & 32 \\
\hline & & - Inovasi Produk & 2 & 1 & 1 & 1 & 2 & 1 & 1 & 1 & 3 & 3 & 3 & 3 & 22 \\
\hline & & - Aliran Bahan Baku Keluar Masuk & 3 & 3 & 2 & 2 & 1 & 1 & 1 & 1 & 3 & 3 & 2 & 2 & 24 \\
\hline \multirow{2}{*}{4} & \multirow{2}{*}{$\begin{array}{l}\text { Keramahan } \\
\text { Lingkungan }\end{array}$} & - Dapat Diperbarui & 3 & 3 & 3 & 3 & 1 & 1 & 1 & 1 & 1 & 1 & 3 & 1 & 22 \\
\hline & & - Kelestarian Lingkungan & 3 & 3 & 3 & 3 & 1 & 1 & 1 & 1 & 3 & 3 & 3 & 2 & 27 \\
\hline \multirow{2}{*}{5} & \multirow{2}{*}{ Unsur Sosial Budaya } & - Memiliki Nilai Sejarah dan Budaya & 3 & 3 & 2 & 2 & 3 & 3 & 3 & 2 & 1 & 3 & 2 & 3 & 30 \\
\hline & & - Identitas Produk Daerah & 3 & 2 & 1 & 1 & 3 & 3 & 3 & 1 & 2 & 2 & 2 & 3 & 26 \\
\hline \multirow{4}{*}{6} & \multirow{4}{*}{ Penguasaan Pasar } & - Lokal/Regional/Nasional/Global & 2 & 1 & 1 & 1 & 3 & 3 & 3 & 2 & 3 & 3 & 1 & 2 & 25 \\
\hline & & - Ragam Pembeli & 3 & 1 & 3 & 3 & 2 & 2 & 2 & 2 & 3 & 3 & 2 & 2 & 28 \\
\hline & & - Karakteristik dan Potensi Pasar & 3 & 1 & 3 & 3 & 3 & 2 & 2 & 2 & 3 & 3 & 2 & 2 & 29 \\
\hline & & - Potensi Pengembangan & 3 & 1 & 3 & 3 & 3 & 2 & 2 & 2 & 2 & 3 & 2 & 2 & 28 \\
\hline \multirow{2}{*}{7} & \multirow{2}{*}{$\begin{array}{l}\text { Ketersediaan bahan } \\
\text { Baku }\end{array}$} & - Jaminan Ketersediaan Bahan Baku & 3 & 3 & 3 & 3 & 3 & 3 & 3 & 3 & 3 & 3 & 2 & 2 & 34 \\
\hline & & - Stabilitas Harga Bahan Baku & 3 & 3 & 3 & 3 & 3 & 3 & 3 & 3 & 1 & 3 & 2 & 1 & 31 \\
\hline \multirow{2}{*}{8} & \multirow{2}{*}{ Dukungan Modal } & - Kelancaran Dana Investasi \& Modal & 3 & 3 & 2 & 3 & 3 & 3 & 3 & 2 & 3 & 3 & 2 & 2 & 32 \\
\hline & & - Modal Sendiri atau Pinjaman & 3 & 3 & 3 & 3 & 3 & 2 & 3 & 3 & 2 & 2 & 3 & 2 & 32 \\
\hline \multirow{2}{*}{9} & \multirow{2}{*}{$\begin{array}{l}\text { Sarana dan Prasarana } \\
\text { Produksi }\end{array}$} & - Mudah Memperoleh Sarana Produksi & 3 & 3 & 3 & 2 & 2 & 2 & 3 & 3 & 2 & 3 & 3 & 2 & 31 \\
\hline & & - Produksi Terpisah dari Rumah & 1 & 1 & 2 & 2 & 3 & 3 & 3 & 1 & 3 & 3 & 2 & 2 & 26 \\
\hline \multirow{3}{*}{10} & \multirow{3}{*}{ Teknologi } & - Akses Teknologi & 1 & 1 & 1 & 1 & 2 & 2 & 2 & 2 & 3 & 3 & 2 & 3 & 23 \\
\hline & & - Otomasi Teknologi & 1 & 1 & 1 & 1 & 1 & 2 & 1 & 1 & 3 & 3 & 2 & 2 & 19 \\
\hline & & - Pengembangan TTG & 1 & 2 & 1 & 1 & 1 & 1 & 1 & 1 & 1 & 1 & 2 & 2 & 15 \\
\hline \multirow{4}{*}{11} & \multirow{4}{*}{ Manajemen Usaha } & - Catatan Keuangan & 2 & 1 & 1 & 1 & 1 & 1 & 1 & 1 & 3 & 3 & 1 & 2 & 18 \\
\hline & & - Legalitas Usaha & 3 & 1 & 1 & 1 & 2 & 1 & 1 & 1 & 3 & 3 & 3 & 3 & 23 \\
\hline & & - Sistem Penggajian & 2 & 1 & 1 & 1 & 1 & 1 & 1 & 1 & 3 & 3 & 2 & 2 & 19 \\
\hline & & - Memiliki Rencana Produksi & 3 & 2 & 1 & 1 & 1 & 1 & 1 & 1 & 3 & 3 & 2 & 2 & 21 \\
\hline & & - Proyeksi Keuntungan & 3 & 3 & 3 & 2 & 2 & 3 & 3 & 1 & 3 & 1 & 1 & 2 & 27 \\
\hline 12 & Harga dan Keuntungan & - Keterjangkauan Harga & 3 & 3 & 3 & 3 & 2 & 3 & 3 & 3 & 3 & 2 & 2 & 2 & 32 \\
\hline & & or Total & 92 & 81 & 77 & 77 & 70 & 78 & 78 & 64 & 87 & 84 & 75 & 77 & \\
\hline
\end{tabular}


Dari hasil penilaian masing-masing indikator kriteria produk unggulan diperoleh ketersediaan bahan baku menjadi indikator dengan skor tertinggi yaitu 34. Hal ini menegaskan bahwa produk-produk unggulan di Bondowoso ditopang oleh bahan baku daerah setempat. Peringkat kedua, indikator yang paling dominan adalah ketersediaan SDM lokal, andalan pendapatan masyarakat, permodalan dan keterjangkauan harga produk masing-masing dengan skor 32. Peringkat ketiga ditempati oleh indikator bahan baku lokal, stabilitas harga bahan baku dan kemudahan dalam memperoleh sarana prasarana produksi dengan skor masing-masing 31 .

Setelah dilakukan scoring dan pemeringkatan dari masing-masing sentra industri kecil menengah yang menghasilkan produk-produk unggulan di Kabupaten Bondowoso, diperoleh sentra industri tape yang memperoleh nilai tertinggi dengan nilai 92. Peringkat berikutnya ditempati sentra industri bordir dengan nilai 87. Sentra dengan peringkat ketiga sebagai penghasil produk unggulan daerah adalah batik dengan nilai 84. Sedangkan yang menempati posisi keempat adalah sentra industri besek atau bernyet dengan skor 81 .

Sentra industri tape layak memperoleh nilai atau skor tinggi (92) karena dari semua variabel kriteria produk unggulan berdasarkan Permendagri Nomor 9 Tahun 2014 sentra ini dinilai paling layak. Dari sisi pengelolaan usaha, produk dan proses produksi, sentra industri ini memperoleh nilai yang cukup besar. Nilai ini menggambarkan kinerja yang baik dalam manajemen usaha yang ditandai dengan pengelolaan keuangan yang tertata dan kelengkapan legalitas usaha. Produk yang dihasilkan berkualitas dan memiliki potensi inovasi yang tinggi di masa mendatang. Pada proses produksi juga menggambarkan pengelolaan yang baik meskipun sederhana dan tempat produksi masih menjadi dengan rumah tempat tinggal.

Dari sisi integrasi kebelakang, sentra tape ini memanfaatkan potensi lokal sepenuhnya. Integrasi kedepan, yang meliputi aspek pemasaran dan penjualan menunjukkan adanya potensi yang besar dan terus berkembang. Pasar yang dilayani oleh sentra industri tape ini tidak hanya di Kabupaten Bondowoso semata, tetapi sudah mencapai beberapa daerah lain. Selain itu, produk tape ini memiliki potensi inovasi dan pengembangan produk yang besar antara lain: tape bakar, tape goreng, bolu tape, tape kukus, donat tape, kue tape keju dan lain-lain yang memiliki usia produk lebih panjang sehingga dapat menjangkau pasar yang lebih luas.

\section{KESIMPULAN DAN SARAN}

Dari hasil pembahasan dapat disimpulkan bahwa sentra industri yang layak disebut dan ditetapkan sebagai Produk Unggulan Daerah Kabupaten Bondowoso adalah tape. Produk tape ini dipilih karena paling memenuhi kriteria sebagai produk unggulan sesuai Permendagri Nomor 9 tahun 2014. Dari sisi internal, sentra tape ini memiliki stabilitas manajemen dari segi keuangan, produksi, dan SDM. Dari sisi eksternal (integrasi kebelakang) menunjukkan adanya pemberdayaan masyarakat lokal dalam pemenuhan kebutuhan bahan baku. Sedangkan dari sisi integrasi kedepan yang berkaitan dengan distribusi dan penguasaan pasar juga menunjukkan kondisi yang baik dan terus berkembang. Setelah diketahui tape menjadi produk unggulan daerah, maka disarankan pemerintah dan stakeholders perlu mengembangkan dan mensosialisasikan tape sebagai icon atau brand dari Kabupaten Bondowoso untuk mendukung Bondowoso sebagai obyek wisata bagi wisatawan domestik dan mancanegara.

\section{DAFTAR PUSTAKA}

Ahmadjayadi, C. (2001). Profil Produk Unggulan Daerah. Kabupaten Purbalingga.

Alkadri, Muchdie, \& Suhandojo. (2001). Tiga Pilar dalam Pengembangan Wilayah: Sumberdaya Alam, Sumberdaya Manusia, dan Teknologi. Jakarta: Pustaka Utama.

Ambardi, U. M., \& Socia, P. (2002). Pengembangan Wilayah dan Otonomi Daerah. Pusat Pengkajian Kebijakan Pengembangan Wilayah (P2KTPW-BPPT), Jakarta.

Donaher, E., \& Lynes, J. (2017). Is Local produce more expensive? Challenging perceptions of price in local food systems. LOCAL ENVIRONMENT, 22(6), 746-763. 
Hobohm, S. (2017). Small and Medium-Sized Enterprises in Economic Development: The UNIDO Experience. Retrieved from http://www.sesric.org: http://www.sesric.org/files/article/157.pdf

Husen, S. (2011). Pengaruh pengeluaran agregat dalam mendorong pertumbuhan produk domestik bruto dan implikasinya terhadap kesejahteraan sosial. Ekonomi Pembangunan, 12(1), 130-158.

Indriani, J., \& Kuswoyo, C. (2017). Pengaruh city branding pada city image dan keputusan berkunjung wisatawan ke Kabupaten Purwakarta. Jurnal Manajemen Maranatha, 17(1), 41-52, November 2017. Program Studi Manajemen, Fakultas Ekonomi, Universitas Kristen Maranatha.

Karadag, H. (2016). The role of SME's and entrepreneurship on economic growth in emerging economies within the post-crisis era: An analysis from Turkey. Journal of Small Business and Entrepreneurship Development, 4(1), 22-31.

McMillan, J. H., \& Schumacher, S. (2001). Research in Education. New York: Longman, Inc.

Messely, L., Dessein, J., \& Lauwers, a. L. (2009). Branding Regional Identity as a Driver for Rural Development. Serbia: Belgrad.

Nakagawa, R. (2012). The policy approach in promoting small and medium sized enterprises in Japan. The International Business and Economic Research Journal, 11(10).

Niskha, M., \& Vesala, K. (2013). SME policy implementation as a relational challenge. entrepreneurship and regional development. An International Journal, 25(5-6).

Oduntan, K. O. (2014). The role of small and medium enterprises in economic development: The Nigerian experience. International Conference on Arts, Economics and Management (ICAEM'14), 75-78. Dubai: Internatonal Centre of Economics, Humanities and management.

Pantow, S. Palar, S. \& Wauran, P. (2015). Analisis Potensi unggulan dan daya saing sub sektor pertanian di Kabupaten Minahasa. Jurnal Berkala Ilmiah Efisiensi, 15(4).

Peraturan Menteri Dalam Negeri RI Nomor 9 Tahun 2014 tentang Pedoman Pengembangan Produk Unggulan Daerah.

Rahmawati, J., \& N. L. (2015). Pengaruh city branding terhadap image of urban destination dan dampaknya pada post-visit behavior. Trikonomika, 14(1), 66-75.

Salisbury, K., Curtis, K., Pozo, V., \& Durward, C. (2018). Is local produce really more expensive? A comparison of direct market conventional grocery produce. Journal of Food Distribution Research, 49(1), 13-21.

Sambajee, P., \& Dhomun, M. Z. (2015). Government and SME's in the Maldives and Mauritius. International Journal of Entrepreneurial Behavior \& Research, 21(6).

Schumann, F. (2016). One village one product (OVOP) strategy and workforce development: lessons for small islands and rural communities. Pacific Asia Inquiry, 7(1), 89-105.

Syafaat, N., \& Supena, F. (2000). Analisis dampak krisis ekonomi terhadap kesempatan kerja dan identifikasi komoditas andalan sektor pertanian di wilayah Sulawesi: Pendekatan input-output. Ekonomi dan Keuangan Indonesia, XLVIII(4).

Takdir, M. (2012). Nasionalisme dalam Bingkai Pluralitas Bangsa: Paradigma Pembangunan \& Kemandirian Bangsa. Yogyakarta: Ar-Ruzz Media

Triharini, M., Larasati, D., \& Susanto, R. (2014). Pendekatan one village one product (OVOP) untuk mengembangkan potensi kerajinan daerah studi kasus: Kerajinan gerabah di Kecamatan Plered, Kabupaten Purwakarta. ITB J. Vis. Art \& Des, 6(1), 2012.

Zalesko, E. (2017). Regional and traditional product as instruments for supporting the economic development of the region (On the example of the Podlaskie Voivodeship). Polityka Ekonomiczna, (487). 